\title{
Toxicidade subaguda do extrato etanólico das folhas de Myracrodruon urundeuva sobre o ciclo estral de ratas Wistar
}

OLIVEIRA, J.M.G.'; PEREIRA, L.J.C.2; MOURA, E.R.2; SOUSA, M.R.S.C.2; SALES, P.A.B.2; SILVA, S.M.M.S."; LIRA, S.R.S.2; COSTA, A.P.R. ${ }^{*}$

'Universidade Federal do Piauí, Campus Professora Cinobelina Elvas, Departamento de Medicina veterinária, 64900-000, Bom Jesus-PI - Brasil; ' ${ }^{C}$ Centro de Ciências Agrárias, Universidade Federal do Piauí, Campus da Socopo, Departamento de Morfofisiologia Veterinária, 64049-550, Teresina-PI, Brasil; ${ }^{3}$ Centro de Ciências Agrárias, Universidade Federal do Piauí, Campus da Socopo, Departamento de Clínica e Cirurgia Veterinária, 64049-550, Teresina-PI, Brasil. *Autor para correspondência: amilfox@uol.com.br

RESUMO: A fitoterapia, abrangendo o uso popular e empírico de plantas medicinais no combate e prevenção de doenças, deve ser aliada a estudos científicos que comprovem a eficácia e segurança desses compostos. No Brasil, a ampla biodiversidade vegetal da região nordeste favorece o uso e estudo de plantas com potenciais terapêuticos. AAroeira do Sertão (Myracrodruon urundeuva Allem.) é uma espécie pertencente à família Anacardiaceae, comum no semiárido, desde o Piauí até Minas Gerais. Seu uso é diverso e disseminado por todo o País, sendo indispensáveis estudos de suas potencialidades e riscos. Devido à ampla utilização da Myracrodruon Urundeuva de forma empírica, este trabalho tem por objetivo a pesquisa de efeitos tóxicos com doses repetidas do extrato etanólico de Myracrodruon urundeuva Allem. (EEMU) e sua influência no ciclo estral de ratas Wistar. No protocolo de toxicidade subaguda foram utilizadas 25 ratas Wistar, divididas em 5 grupos $(n=5)$, tratadas com diferentes doses do EEMU $(125,250,500$ e $1000 \mathrm{mg} / \mathrm{kg}$ ) e água destilada (controle) por um período de 28 dias. Nesse período foram realizadas mensurações do consumo de água e ração e avaliação comportamental. Esses animais foram avaliados diariamente quanto a fase do ciclo estral, por meio de esfregaço vaginal a fresco, sendo observada a frequência de cada fase bem como o intervalo interestro. As ratas foram anestesiadas e o sangue foi coletado para a realização dos ensaios bioquímicos. Em seguida, foram eutanasiadas para coleta e avaliação dos órgãos internos. Durante o período de avaliação, não foram observadas alterações de comportamento, nem de consumo de água ou ração. A evolução ponderal dos animais não diferiu entre os grupos tratados. A concentração sérica de ALT foi maior nos animais tratados com EEMU $1000 \mathrm{mg} / \mathrm{kg}$. As ratas tratadas com o extrato não apresentaram alterações significativas na frequência das fases do ciclo estral bem como duração do estro e intervalo entre estros, quando comparadas ao grupo controle. Os resultados obtidos neste estudo não apontam alterações tóxicas significativas, sistêmicas ou sobre o ciclo estral, de ratas Wistar tratadas com o extrato, nas doses avaliadas, por um período de 28 dias.

Palavras-chave: Myracrodruon urundeuva, ciclicidade, toxicidade, extrato.

\begin{abstract}
Subacute toxicity ofMyracrodruon urundeuva leave ethanolic extract and its effects on the estrous cycle of female Wistar rats. The herbal medicine, comprising the popular and empirical use of medicinal plants in combating and preventing diseases, should be combined with scientific studies that prove the effectiveness and safety of these compounds. In Brazil, the vast plant biodiversity of the Northeast favors the use and study of plants with therapeutic potential. Aroeira (Myracrodruon urundeuva Allem.) is a species of the Anacardiaceae family, common in the semiarid region, from Piauí to Minas Gerais. Its use is diverse and widespread throughout the country, making studies of its potential and risks necessary. Due to the wide use of Myracrodruon urundeuva in an empirical form, this paper aims to research toxic effects with repeated doses of Myracrodruon urundeuva Allem.ethanol extract (EEMU) and its influence on the estrous cycle of female Wistar rats. In a subacute toxicity protocol 35 female Wistar rats were used, divided into 5 groups $(n=5)$ treated with different doses of
\end{abstract}

Recebido para publicação em 05/08/2015 
EEMU $(125,250,500$ and $1000 \mathrm{mg} / \mathrm{kg}$ ) and distilled water (control) for 28 days. In this period measurements of water intake, feed consumption were carried out and a behavioral assessment was performed. The estrous cycles of these animals were evaluated daily by fresh vaginal smear, it the frequency of each phase as well as the inter-estrus intervals were observed. The rats were anesthetized and blood was collected for the biochemical assays. Then they were euthanized for the collection and evaluation of internal organs. During the evaluation period, there were no observed behavioral changes nor were the water or food consumption variations. The weight gain of the animals did not differ between treatment groups. The serum ALT was higher in animals treated with EEMU $1000 \mathrm{mg} / \mathrm{kg}$. The rats treated with the extract showed no significant changes in the frequency of the phases of the estrous cycle, estrus duration and estrus interval when compared to the control group. The results of this study do not indicate significant toxic alterations, neither systemic nor on the estrous cycle in female rats treated with the extract, at the evaluated doses, over a period of 28 days.

Key words: Myracrodruon urundeuva, cyclicity, toxicity, extract.

\section{INTRODUÇÃO}

O poder curativo das plantas é tão antigo quanto o aparecimento da espécie humana na terra. Desde cedo as primeiras civilizações perceberam que algumas plantas continham, em suas essências, princípios ativos os quais ao serem experimentados no combate às doenças revelaram empiricamente seu poder curativo (Badke et al., 2011). Embora a medicina tenha se especializado e desenvolvido inúmeros métodos no tratamento de doenças, muitos ainda preferem utilizar plantas in natura como um recurso natural e acessível para manter a saúde (Calixto, 2000).

Contudo, as pesquisas com plantas medicinais devem envolver investigações da medicina tradicional e popular (etnobotânica); isolamento, purificação e caracterização de princípios ativos (química orgânica: fitoquímica); investigação farmacológica de extratos e dos constituintes químicos isolados (farmacologia); transformações químicas de princípios ativos (química orgânica sintética); estudo da relação estrutura/ atividade e dos mecanismos de ação dos princípios ativos (química medicina) e a operação de formulações para a produção de fitoterápicos. A integração destas áreas na pesquisa de plantas medicinais conduz a um caminho promissor e eficaz para descobertas de novos medicamentos (Maciel et al., 2002).

Myracrodruon urundeuva é uma espécie arbórea pertencente à família Anacardiaceae, conhecida popularmente como aroeira, que ocorre naturalmente no Brasil, na Bolívia, no Paraguai e na Argentina (Santin \& Leitão Filho, 1991). Sua entrecasca possui propriedades antiinflamatórias, adstringentes, antialérgicas e cicatrizantes (Viana et al., 1995). Os taninos presentes na entrecasca da aroeira demonstraram atividade antiulcerogênica e gastroprotetora (Viana et al., 2007). A M. urundeuva possui, também, atividades antibacteriana e antifúngicas (Sá et al., 2009).

O extrato etanólico das folhas de $M$. urundeuva demonstrou baixa toxicidade in vitro e ações estrogênica na dose de $125 \mathrm{mg} / \mathrm{kg}$ e antiestrogênica na dose de $1000 \mathrm{mg} / \mathrm{kg}$ (Oliveira, 2013).

Devido à ampla utilização de forma empírica e as inúmeras atividades farmacológicas já comprovadas da Myracrodruon urundeuva, e tendo em vista o número reduzido de estudos referentes à sua toxicidade reprodutiva, o presente trabalho tem por objetivo a pesquisa de efeitos tóxicos com doses repetidas do extrato etanólico de Myracrodruon urundeuva Allem. e sua influência no ciclo estral de ratas Wistar.

\section{MATERIAL E MÉTODOS}

\section{Processamento do material vegetal}

As folhas de aroeira (Myracrodruon urundeuva) foram coletadas no mês de novembro/2011 no Centro de Ciências Agrárias da Universidade Federal do Piauí, cidade de Teresina-PI. A exsicata da planta encontra-se depositada sob o número 29.026, no Herbário Graziela Barroso - Universidade Federal do Piauí. O material vegetal foi seco à temperatura ambiente e moído em moinho de facas até a obtenção de um pó fino $(2256 \mathrm{~g})$. O extrato foi obtido por maceração do pó com etanol PA, a uma proporção $7: 1 \mathrm{v}: \mathrm{m}$. A solução foi mantida em ambiente seco e ventilado, ao abrigo da luz, sendo agitada diariamente durante 15 dias. 0 extrato foi filtrado através de papel de filtro e concentrado em evaporador rotativo (Quimis 344B2) a $40^{\circ} \mathrm{C}$ e à pressão reduzida. O material concentrado foi mantido sob refrigeração e depois liofilizado e conservado à temperatura de $4-8^{\circ} \mathrm{C}$. 


\section{Animais}

Para a realização dos experimentos foram utilizadas ratas (Rattus norvegicus, linhagem Wistar) fêmeas adultas (aproximadamente 90 dias de vida) e virgens, pesando entre 190 e $250 \mathrm{~g}$ provenientes do Biotério de Manutenção de Animais Destinados a Experimentação do Departamento de Morfofisiologia Veterinária-CCA/UFPI (Biomadex). Os animais foram alojados em gaiolas-padrão de polipropileno de $49 \times 31 \times 21 \mathrm{~cm}$ (lotação de 4 animais), forradas com cama de maravalha, trocadas duas vezes por semana, e com água potável e ração ad libitum, mantidos em ambiente climatizado $\left(24 \pm 1^{\circ} \mathrm{C}\right)$, com ciclo claro/escuro de $12 \mathrm{~h}$ e com sistema de exaustão com 15 a 20 trocas de ar/h controlando a dispersão de amônia no ambiente. Os protocolos experimentais realizados foram aprovados pelo Comitê de Ética em Experimentação com Animais da UFPI (Número do protocolo 035/14).

\section{Toxicidade Subaguda}

O protocolo de toxicidade subaguda foi desenvolvido conforme o Guia OECD-407/1995 "Repeat-dose 28 days oral toxicity study in rodents" (OECD, 1995). Foram utilizadas 25 ratas Wistar, divididas em 5 grupos $(n=5)$, tratadas diariamente, uma vez ao dia, via gavagem, com extrato etanólico de Myracrodruon urundeuva Allem. (EEMU) nas doses de 125, 250, 500 e $1000 \mathrm{mg} / \mathrm{kg}$ e água destilada (controle) no volume de $10 \mathrm{ml} / \mathrm{kg}$ por um período de 28 dias. Nesse período foi realizada a mensuração do consumo individual de água e ração e avaliação comportamental (estado de alerta, sedação, ptose, dispnéia, diarréia, convulsão, atividade motora espontânea, reflexo postural, piloereção e resposta ao tato) (Cunha et al., 2013). O ganho de peso foi registrado a cada três dias e ao final do período de observação, as ratas foram anestesiadas (associação de $80 \mathrm{mg}$ de Cetamina $+10 \mathrm{mg}$ de Xilazina por kg, via intraperitoneal) e colocadas em decúbito dorsal, sendo então submetidos à punção intracardíaca para coleta do sangue, o qual foi acondicionado em tubos sem anticoagulante, com ativador de coágulo. As amostras de sangue coletadas foram centrifugadas a $1465 \mathrm{~g}$ por 5 minutos para a obtenção do soro. As determinações bioquímicas foram realizadas por química úmida (Labtest, Belo Horizonte) e os parâmetros séricos ALT (alanina aminotransferase), creatinina, uréia e fosfatase alcalina foram avaliados (Ferreira et al., 2013).

As ratas foram eutanasiadas por aprofundamento do plano anestésico (Tiopental sódico, $150 \mathrm{mg} / \mathrm{Kg}$ ) e os órgãos internos (coração, pulmão, baço, adrenais, rins, fígado, ovários, útero e mama) foram coletados, pesados e avaliados macroscopicamente com o auxílio de uma lupa. O útero e ovários foram submetidos ao processamento histológico por desidratação com séries crescentes de álcool (70 a 100\%), diafanização em xilol, impregnação e inclusão em parafina. Em micrótomo, os fragmentos tissulares foram cortados em espessura de 5,0 $\mu \mathrm{M}$, corados com hematoxilinaeosina e examinados ao microscópio de luz (Bacha \& Wood 1990).

$\mathrm{Na}$ área total abrangida pela secção histológica dos ovários, foi quantificado o número total de folículos primordiais, primários, secundários, terciários e atrésicos, bem como o de corpos lúteos. A contagem foi realizada baseando-se na caracterização dos folículos ovarianos seguindo descrição de Eurell \& Frapper (2012). O cornos uterinos de cada animal foi seccionado transversalmente e analisados histopatologicamente para observação de lesões ou alterações.

\section{Ciclo Estral}

Durante o período de avaliação da toxicidade subaguda, as ratas foram avaliadas diariamente (entre 8:00 e 9:00 h) quanto a fase do ciclo estral por meio de esfregaço vaginal a fresco. Foi realizado o lavado vaginal pela introdução de uma micropipeta contendo $10 \mu \mathrm{L}$ de solução de cloreto de sódio a $0,9 \%$ e imediata recuperação. O material coletado foi, imediatamente, depositado sobre uma lâmina de vidro e analisado por meio de microscopia de luz, nas objetivas de 10 e 40x. As fases do ciclo estral (estro, diestro, proestro e metaestro) foram registradas de acordo com a proporção relativa dos tipos celulares (células epiteliais nucleadas, células epiteliais cornificadas e leucócitos) presentes no esfregaço, utilizando a ferramenta de identificação proposta por Byers et al. (2012). Os resultados individuais foram registrados e a frequência de cada fase, bem como o intervalo interestro foram determinados. O ciclo estral da rata dura entre 4 e 5 dias, podendo ser considerado prolongado se a rata permanecer em uma fase por mais de 4 dias (Nayanatara et al.,2012).

\section{Análise estatística}

Os valores obtidos foram expressos como média $\pm E P M$ e, os dados submetidos à análise de variância ANOVA(One Way) seguido do pós-teste de Tukey adotando o nível de significância estatística $p<$ 0,05 . Os gráficos foram confeccionados utilizando o programa Graphpad Prism® versão 5.0.

\section{RESULTADOS}

\section{Toxicidade Subaguda}

Durante o período de tratamento, os animais não manifestaram alterações comportamentais visíveis e o ganho de peso ao longo do período não diferiu entre os grupos (Figura 1). 
Não houve diferença estatística significativa entre os grupos avaliados quanto ao consumo de água e ração (Tabela 1). Na análise macroscópica os órgãos (coração, pulmão, rins, adrenais, baço, fígado, útero, ovários e mama) não apresentaram alterações patológicas aparentes. A massa relativa não diferiu entre os grupos, com exceção das adrenais dos animais tratados com EEMU na dose de $125 \mathrm{mg} / \mathrm{kg}$ que apresentaram um aumento significativo em relação ao grupo controle (Tabela 2).
Os resultados do efeito do EEMU sobre os parâmetros bioquímicos estão dispostos na tabela 3. Houve um aumento significativo nos níveis de ALT (alanina aminotransferase) dos animais tratados com EEMU $1000 \mathrm{mg} / \mathrm{kg}$, quando comparados ao grupo controle.

A tabela 4 mostra o número de estruturas ovarianas quantificadas. Não foram observadas alterações histológicas no útero e ovários dos animais avaliados nesse experimento (Figura 2).

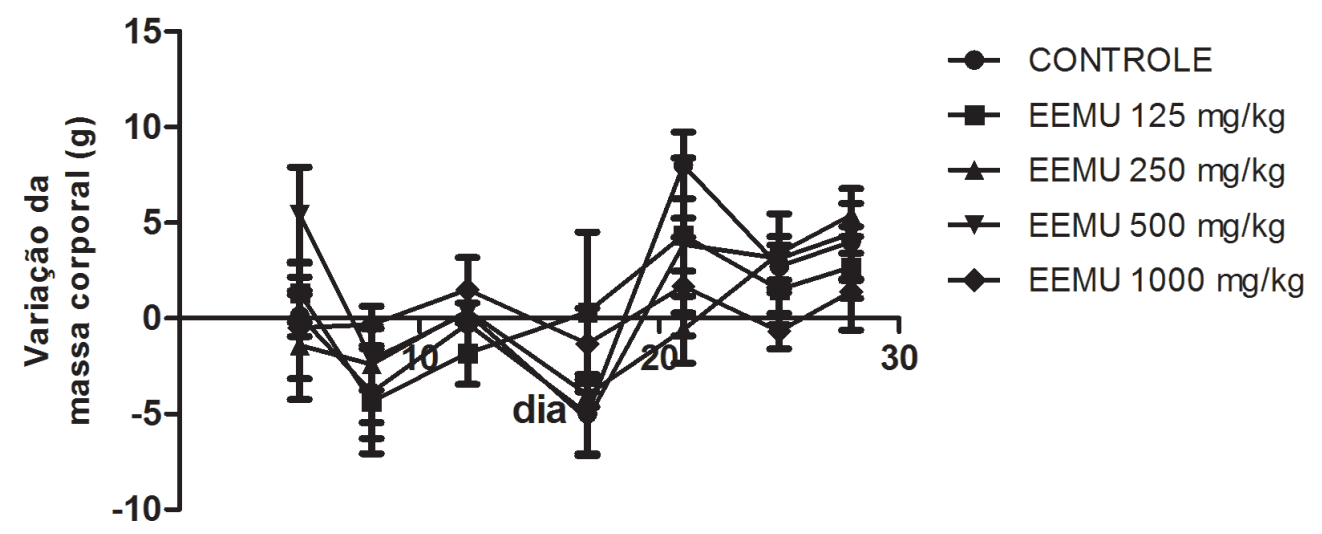

FIGURA 1. Ganho de peso de ratas Wistar tratadas por via oral, com extrato etanólico das folhas de M. urundeuva (EEMU) nas doses 125, 250, 500 e 1000 mg/kg durante 28 dias. Os valores representam a média \pm E.P.M.

TABELA 1. Consumo médio diário individual de água e ração por ratas Wistar tratadas por via oral, com controle e extrato etanólico das folhas de M. urundeuva (EEMU) nas doses 125, 250, 500 e $1000 \mathrm{mg} / \mathrm{kg}$ durante 28 dias

\begin{tabular}{ccc}
\hline & & Parâmetro \\
Tratamento & Água $(\mathbf{m L}) / \mathbf{2 4} \mathbf{~ h}$ & Ração $(\mathbf{g}) / \mathbf{2 4} \mathbf{~}$ \\
\hline Controle & $36,34 \pm 2,03$ & $20,71 \pm 1,16$ \\
EEMU 125 & $38,07 \pm 3,18$ & $19,33 \pm 0,99$ \\
EEMU 250 & $37,32 \pm 2,75$ & $19,69 \pm 0,90$ \\
EEMU 500 & $39,13 \pm 2,70$ & $21,1 \pm 0,93$ \\
EEMU 1000 & $33,99 \pm 2,40$ & $19,54 \pm 0,82$ \\
\hline
\end{tabular}

Os valores representam a média \pm E.P.M. do número de animais usados no experimento.

TABELA 2. Massa relativa ( $\mathrm{mg} / 100 \mathrm{~g}$ de peso corporal) dos órgãos de ratas Wistar tratadas por via oral, com extrato etanólico das folhas de M. urundeuva (EEMU) nas doses 125, 250, 500 e $1000 \mathrm{mg} / \mathrm{kg}$ durante 28 dias

\begin{tabular}{llllll}
\hline \multirow{2}{*}{ Órgão } & \multicolumn{5}{c}{ Tratamentos } \\
\cline { 2 - 6 } & Controle & EEMU 125 & EEMU 250 & EEMU 500 & EEMU 1000 \\
\hline Coração & $0,34 \pm 0,01$ & $0,36 \pm 0,02$ & $0,37 \pm 0,01$ & $0,38 \pm 0,02$ & $0,34 \pm 0,02$ \\
Pulmão & $0,92 \pm 0,11$ & $0,86 \pm 0,07$ & $0,86 \pm 0,03$ & $0,94 \pm 0,12$ & $0,82 \pm 0,02$ \\
Adrenais & $0,02 \pm 0,00$ & $0,03 \pm 0,00^{a}$ & $0,03 \pm 0,00$ & $0,03 \pm 0,00$ & $0,03 \pm 0,00$ \\
Rins & $0,69 \pm 0,03$ & $0,75 \pm 0,05$ & $0,73 \pm 0,01$ & $0,76 \pm 0,03$ & $0,69 \pm 0,03$ \\
Baço & $0,28 \pm 0,02$ & $0,27 \pm 0,01$ & $0,25 \pm 0,02$ & $0,28 \pm 0,02$ & $0,28 \pm 0,02$ \\
Fígado & $2,59 \pm 0,18$ & $2,51 \pm 0,06$ & $2,81 \pm 0,13$ & $2,73 \pm 0,11$ & $2,42 \pm 0,09$ \\
Útero & $0,29 \pm 0,04$ & $0,37 \pm 0,04$ & $0,34 \pm 0,05$ & $0,44 \pm 0,05$ & $0,32 \pm 0,03$ \\
Ovários & $0,05 \pm 0,00$ & $0,05 \pm 0,00$ & $0,04 \pm 0,00$ & $0,04 \pm 0,00$ & $0,05 \pm 0,00$ \\
Mama & $0,02 \pm 0,00$ & $0,02 \pm 0,00$ & $0,01 \pm 0,00$ & $0,01 \pm 0,00$ & $0,02 \pm 0,00$
\end{tabular}

Os valores representam a média \pm E.P.M. do número de animais usados no experimento $(n=5)$. a $p<0,05$, quando comparado ao grupo Controle (ANOVA One-way seguido de Teste de Tukey). 
TABELA 3 - Parâmetros bioquímicos obtidos do soro de ratas Wistar tratadas por via oral, com extrato etanólico das folhas de M. urundeuva (EEMU) nas doses 125, 250, 500 e $1000 \mathrm{mg} / \mathrm{kg}$ durante 28 dias nas doses 125 , 250,500 e $1000 \mathrm{mg} / \mathrm{kg}$ durante 28 dias

\begin{tabular}{lccccc}
\hline \multirow{2}{*}{ Parâmetros } & \multicolumn{5}{c}{ Tratamentos } \\
\cline { 2 - 6 } & Controle & EEMU 125 & EEMU 250 & EEMU 500 & EEMU 1000 \\
\hline Uréia (mg/dL) & $47,72 \pm 7,40$ & $50,22 \pm 9,02$ & $50,52 \pm 3,33$ & $67,45 \pm 5,39$ & $31,80 \pm 7,86$ a \\
\hline Creatinina $(\mathrm{mg} / \mathrm{dL})$ & $0,64 \pm 0,09$ & $0,56 \pm 0,07$ & $0,64 \pm 0,02$ & $0,57 \pm 0,06$ & $0,67 \pm 0,04$ \\
\hline Fosfatase Alcalina $(\mathrm{U} / \mathrm{L})$ & $76,46 \pm 2,47$ & $75,08 \pm 5,54$ & $65,50 \pm 6,19$ & $61,43 \pm 14,33$ & $77,73 \pm 2,79$ \\
\hline ALT (U/L) & $3,30 \pm 1,42^{\mathrm{b}}$ & $3,40 \pm 1,27^{\mathrm{b}}$ & $1,20 \pm 0,28^{\mathrm{a}, \mathrm{b}}$ & $9,67 \pm 1,28$ & $10,75 \pm 2,98$ \\
\hline
\end{tabular}

Os valores representam a média \pm E.P.M. do número de animais usados no experimento $(n=5)$. a $p<0,05$, quando comparados ao grupo EEMU 500; ' ${ }^{p}<0,05$, quando comparados ao grupo EEMU 1000 (ANOVA One-way seguido de Teste de Tukey).

TABELA 4 - Número de estruturas presentes no ovário de ratas Wistar tratadas por via oral, com extrato etanólico das folhas de M. urundeuva (EEMU) nas doses 125, 250 e $500 \mathrm{mg} / \mathrm{kg}$ durante 28 dias

\begin{tabular}{lcccc}
\hline \multirow{2}{*}{ Estrutura } & \multicolumn{4}{c}{ Tratamentos } \\
\cline { 2 - 5 } & Controle & EEMU 125 & EEMU 250 & EEMU 500 \\
\hline Corpo lúteo & $5,50 \pm 2,25$ & $3,25 \pm 0,63$ & $3,25 \pm 1,37$ & $1,25 \pm 0,75$ \\
\hline Folículo primordial & $3,25 \pm 1,31$ & $4,50 \pm 1,32$ & $2,50 \pm 0,50$ & $4,50 \pm 0,96$ \\
\hline Folículo primário & $4,75 \pm 1,18$ & $4,50 \pm 0,95$ & $3,00 \pm 0,41$ & $5,00 \pm 0,71$ \\
\hline Folículo secundário & $2,75 \pm 0,48$ & $3,50 \pm 1,19$ & $3,25 \pm 0,63$ & $2,75 \pm 0,48$ \\
\hline Folículo terciário & $0,50 \pm 0,50$ & $0,25 \pm 0,25$ & $0,00 \pm 0,00$ & $0,00 \pm 0,00$ \\
\hline Folículo atrésico & $1,75 \pm 0,48$ & $2,75 \pm 0,75$ & $3,00 \pm 0,70$ & $3,00 \pm 1,00$ \\
\hline
\end{tabular}

Os valores representam a média \pm E.P.M. do número de animais usados no experimento.

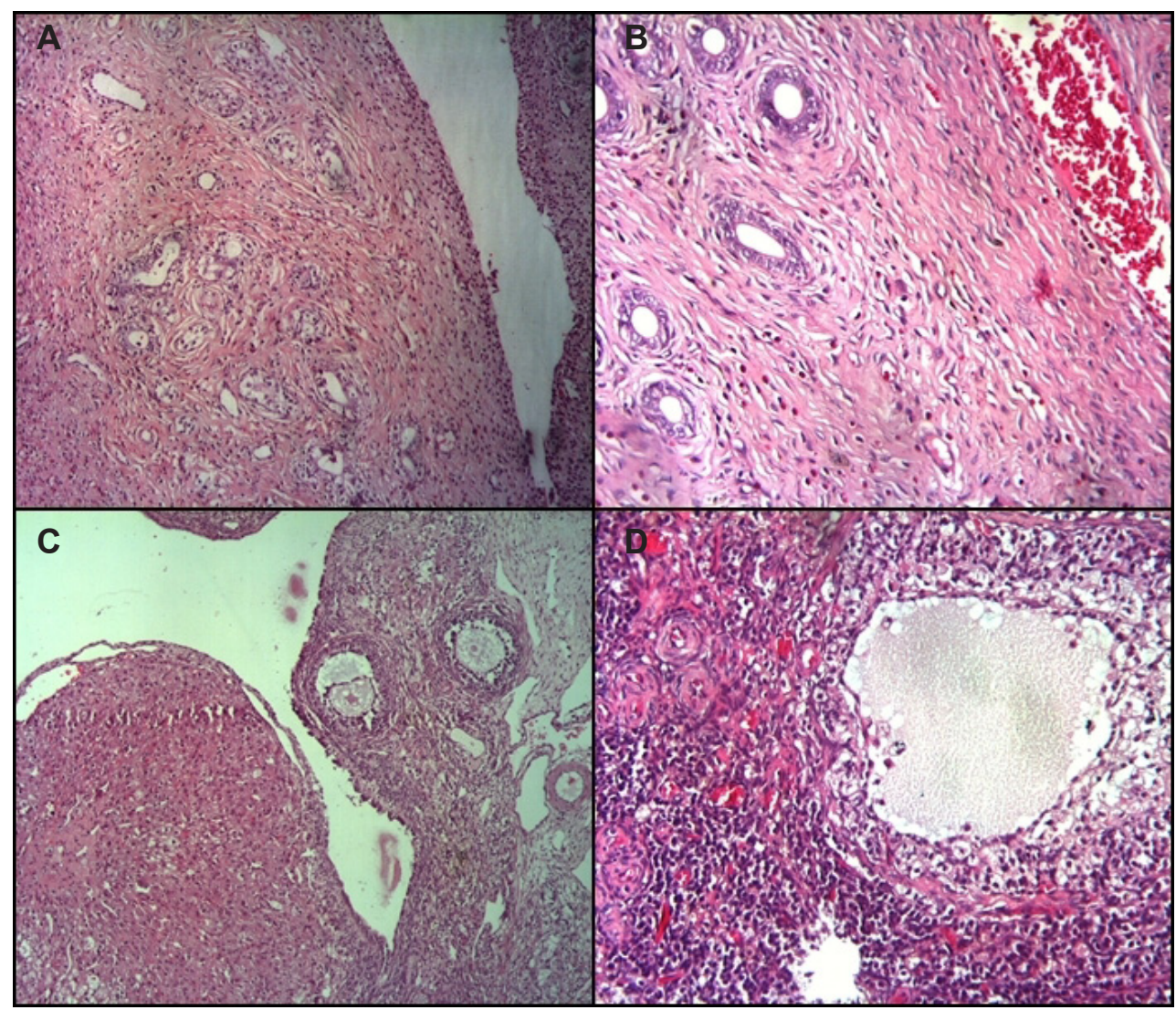

FIGURA 2. Fotomicrografias de ovário e útero de ratas Wistar. A: ovário de uma rata do grupo 1 (controle); B: ovário de uma rata do grupo 4 (EEMU $500 \mathrm{mg} / \mathrm{kg}$ ); C: útero de uma rata do grupo 1 (controle); D: útero de uma rata do grupo 4 (EEMU 500mg/kg) 
A

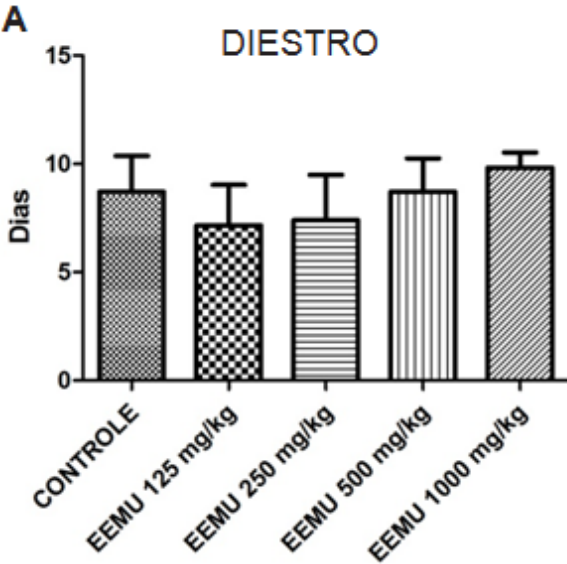

C

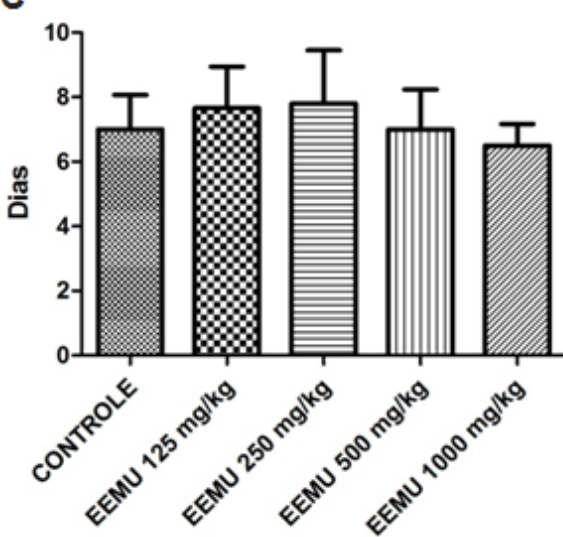

B

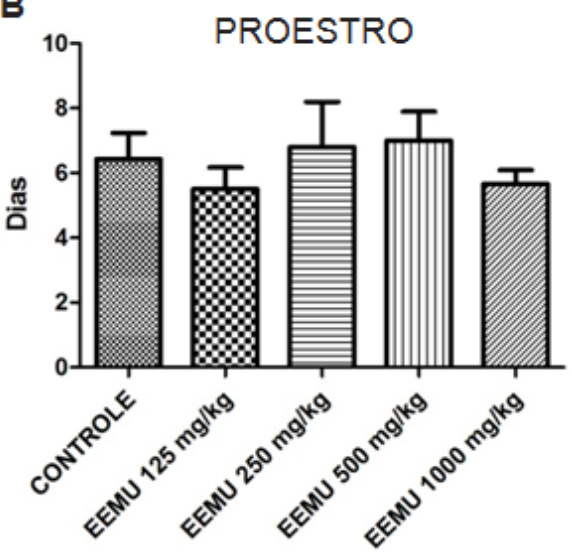

D

METAESTRO

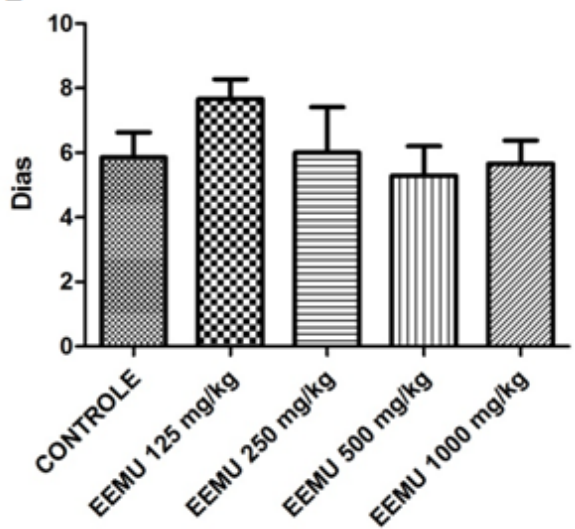

FIGURA 3. Frequência das fases do ciclo estral de ratas Wistar tratadas por via oral, com extrato etanólico das folhas de M. urundeuva (EEMU) nas doses 125, 250, 500 e $1000 \mathrm{mg} / \mathrm{kg}$ durante 28 dias. Os valores representam a média \pm E.P.M em dias do diestro (A), proestro (B), estro (C) e metaestro (D).

TABELA 5. Intervalo interestro (dias) e duração do estro (h) de ratas Wistar tratadas por via oral, com extrato etanólico das folhas de M. urundeuva (EEMU) nas doses 125, 250, 500 e $1000 \mathrm{mg} / \mathrm{kg}$ durante 28 dias

\begin{tabular}{lcc}
\hline Tratamento & $\begin{array}{c}\text { Parâmetro } \\
\text { Intervalo interestro (dias) }\end{array}$ & Duração do estro $(\mathbf{h})$ \\
\hline Controle & $3,40 \pm 0,44$ & $35,11 \pm 4,80$ \\
EEMU $\mathbf{1 2 5}$ & $2,60 \pm 0,38$ & $38,44 \pm 9,92$ \\
EEMU 250 & $2,93 \pm 0,37$ & $37,20 \pm 6,48$ \\
EEMU 500 & $2,83 \pm 0,37$ & $32,38 \pm 2,74$ \\
EEMU $\mathbf{1 0 0 0}$ & $3,50 \pm 0,46$ & $30,58 \pm 3,01$ \\
\hline
\end{tabular}

Os valores representam a média \pm E.P.M. do número de animais usados no experimento.

\section{Ciclo Estral}

Em relação à frequência de fases do ciclo estral, os resultados estão expostos na figura 3. Não houve diferença estatística significativa, em nenhuma das fases, entre os grupos testados. $O$ intervalo interestro e a duração do estro também não foram alterados pelo tratamento com o extrato (Tabela 5).

\section{DISCUSSÃO}

A toxicidade sistêmica se manifesta pela redução do desenvolvimento ponderal, redução nos consumos de água e ração, alterações de comportamento, apatia e má condição da pelagem 
(Mello, 2001; González \& Silva, 2006). O extrato etanólico de Myracrodruon urundeuva (EEMU), nas doses estudadas, não alterou nenhum desses parâmetros, denotando ausência de toxicidade sistêmica, quando administrado por via oral pelo período de 28 dias.

Um requisito importante em experimentos toxicológicos é a capacidade de avaliar os efeitos de xenobióticos em órgãos específicos. Essa avaliação é feita através de exame macroscópico e mensuração do peso dos órgãos e exame histopatológico do tecido. O peso do órgão pode ser o indicador mais sensível do efeito de um composto experimental, já diferenças significativas no peso de órgãos entre animais de grupos tratados e não tratados (controle) pode ocorrer na ausência de quaisquer alterações morfológicas (Bailey et al., 2004). O grupo tratado com EEMU na dose de $125 \mathrm{mg} / \mathrm{kg}$ mostrou um aumento significativo no peso das adrenais quando comparados ao grupo controle. Pelo tamanho diminuto dessas glândulas, muitos fatores podem interferir em alterações nas mensurações das mesmas. Segundo Bailey et al. (2004), as glândulas adrenais e os ovários são melhor avaliados utilizando a razão peso do órgão/ cérebro. Não houve diferença estatística significativa no peso dos demais órgãos dos animais tratados com o EEMU.

As alterações dos parâmetros bioquímicos do soro em seus diversos graus de ocorrência são utilizadas no diagnóstico de toxicidade induzida por drogas, em tecidos específicos (Ramaiah, 2007). Foi observado aumento dos níveis sérico de ALT no grupo de animais tratados com EEMU na maior dose $(1000 \mathrm{mg} / \mathrm{kg})$, todavia esse valor $(10,75 \mathrm{U} / \mathrm{L})$ encontra-se abaixo dos valores de referência entre 26- $60 \mathrm{U} / \mathrm{L}$ e 32-63 U/L sugeridos por Melo et al. (2012) e Lima et al. (2014).

Durante o ciclo estral a maturação e ovulação do folículo pré-ovulatório ocorre sob influência de hormônios ovarianos e extraovarianos. Qualquer alteração nestes hormônios leva a irregularidade na função do ovário e mudanças na duração das fases do ciclo estral (Shivalingappa et al., 2002). A utilização de animais experimentais para o estudo do ciclo reprodutivo feminino já é bem elucidada. Como as ratas possuem ciclos reprodutivos curtos (4 a 5 dias), tornam-se modelos animais ideais para investigar alterações que ocorrem durante o ciclo estral. $O$ estro dura aproximadamente $12 \mathrm{~h}$, geralmente no período escuro, com ovulação espontânea (COBEA, 1996; Spornitz et al., 1999; Marcondes et al., 2002).

Não foram constatadas alterações na frequência das fases do ciclo estral, bem como na duração do estro e intervalo interestro de ratas tratadas com EEMU nas doses de 125, 250, 500 e
$1000 \mathrm{mg} / \mathrm{kg}$ por 28 dias.

A fertilidade da fêmea depende de fatores como o desenvolvimento adequado das gônadas, a maturação do oócito, e a proliferação e diferenciação das células da granulosa bem como da interação entre os fatores endócrinos, autócrinos e parácrinos que coordenam as alterações cíclicas do ovário durante a foliculogênese (Elvin \& Matzuk, 1998). Não foram observadas alterações no número de estruturas ovarianas das ratas tratadas com EEMU, mostrando que o extrato não interfere na foliculogênese.

\section{CONCLUSÃO}

O extrato etanólico das folhas de Myracrodruon urundeuva, nas doses avaliadas, não produz alterações tóxicas significativas, sistêmicas ou sobre o ciclo estral de ratas Wistar tratadas, por via oral, durante 28 dias.

\section{REFERÊNCIAS}

BADKE, M.R. et al. Plantas medicinais: o saber sustentado na prática do cotidiano popular. Escola Anna Nery, v. 15, n. 1, p. 132-9, 2011.

BACHA, W.J.; WOOD. Color atlas of veterinary histology. 1.ed. Philadelphia: Lea \& Febiger, 1990. 269p.

BAILEY, S.A. et al. Relationships Between Organ Weight and Body/ Brain Weight in the Rat: What Is this Best Analytical Endpoint?. Toxicologic Pathology, n. 38, p.448-466, 2004.

BYERS, S. L. et al. Mouse estrous cycle identification tool and images. PLoS One, v. 7, n. 4, p. e35538, 2012.

CALIXTO, B.J.B. Efficacy, safety, quality control, marketing and regulatory guidelines for herbal medicines (phytotherapeutic agents). Brazilian Journal of Medical and Biological Research, v. 33, p. 2, 2000.

COBEA - Colégio Brasileiro de Experimentação Animal. Manual para técnicos em bioterismo . 2 ed. São Paulo: H.A. Rothschild, 1996. 259p.

CUNHA, L. C. et al. Avaliação da toxicidade aguda do extrato aquoso de Apeiba tibourbouAubl (Tiliaceae), em camundongos e ratos. Revista de Ciências Farmacêuticas Básica e Aplicada, v. 34, n. 3, p. 357362, 2013.

ELVIN, J. A.; MATZUK, M. M. Mouse models of ovarian failure. Reviews of reproduction, v. 3, n. 3, p. 183195, 1998.

EURELL, J. A.; FRAPPER, B.L. Histologia Veterinária de Dellmann. 6 ed. São Paulo: Manole, 2012. 412p.

FERREIRA, M. D. et al. Avaliação da toxicidade crônica e gestacional do extrato etanólico de Buchenavia sp., em ratas Wistar. Acta Veterinaria Brasilica, v. 7, n. 4, p. 319-326, 2013.

GONZÁLEZ, F. H. D; SILVA S. C. Introdução à Bioquímica Clínica Veterinária. 2.ed. Porto Alegre: Editora da UFRGS, 2006. 364p.

LIMA, C. M. et al. Valores de referência hematológicos 
e bioquímicos de ratos (Rattus novergicus linhagem Wistar) provenientes do biotério da Universidade Tiradentes. Scientia Plena, v. 10, n. 3, p. 034601, 2014.

MACIEL, M.A.M. et al. Plantas medicinais: a necessidade de estudos multidisciplinares. Química nova, v. 25, n. 3, p. 429-438, 2002.

MARCONDES, F. K.; BIANCHI, F. J.; TANNO, A. P. Determination of the estrous cycle phases of rats: some helpful considerations. Brazilian Journal of Biology, v. 62, n. 4A, p. 609-614, 2002.

MELLO, F. B. Estudo dos efeitos de Lantana camara (Verbenaceae) sobre a fertilidade e reprodução de ratos. 2001. 120p. Dissertação (Mestrado em Ciências Veterinárias, Especialidade: Anestesiologia), Universidade Federal do Rio Grande do Sul. Porto Alegre.

MELO, M. G. D. et al. Valores de referência Hematológicos e Bioquímicos de Ratos (Rattus novergicus linhagem Wistar) provenientes do biotério central da Universidade Federal de Sergipe. Scientia Plena, v.8, n.4, p.049903, 2012.

NAYANATARA, A. K. et al. Effect of cynodon dactylon extract on estrous cycle and reproductive organs in female wistar rats. International Journal of Analytical Biomedical and Pharmaceutical Sciences, v. 1, n. 3, p. 10-15, 2012.

OECD (Organization for economic co-operation and development). Guideline for Testing of Chemicals: Repeat-dose $\mathbf{2 8}$ days oral toxicity study in rodents. Guideline: 407. 1995. 8p.

OLIVEIRA, J. M. G. Determinação da atividade antioxidante e toxicidade in vitro e in vivo de Myracrodruon urundeuva Allem.. 2013.104p.
Dissertação (Mestrado em Farmacologia- Farmacologia de Produtos Naturais) - Programa de Pós Graduação em Farmacologia, Universidade Federal do Piauí, Teresina.

RAMAIAH, S. K. A toxicologist guide to the diagnostic interpretation of hepatic biochemical parameter. Food and Chemical Toxicology, n. 45, p. 15511557, 2007.

SÁ, R. A. et al. Antibacterial and antifungal activities of Myracrodruon urundeuva heartwood. Wood Science Technology, v. 43, p. 85-95, 2009.

SANTIN, D. A.; LEITAO FILHO. H.F. Restabelecimento e revisao taxonomica do genero Myracrodruon Freire Allemao (Anacardiaceae). Revista Brasileira de Botânica, v. 14, n. 2, p. 133-145, 1991.

SHIVALINGAPPA, $\mathrm{H}$. et al. Effect of ethanol extract of Rivea hypocrateriformis on the estrous cycle of the rat. Journal of ethnopharmacology, v. 82, n. 1, p. 11-17, 2002.

SPORNITZ, U. M.; SOCIN, C. D; DRAVID, A. A. Estrous stage determination in rats by means of scanning electron microscopic images of uterine surface epithelium. The Anatomical Record, v. 254, n. 1, p. 116-126, 1999.

VIANA, G. S. B. et al. Analgesic and anti-inflammatory effects of the tannin fraction from Myracrodruon urundeuva Fr All. Phytotherapy Research, v. 11, p. 118-122, 2007.

VIANA, G. S. B. et al. Aroeira-do-sertão (Myracrodruon urundeuva Fr. AII.): estudo botânico, farmacognóstico, químico e farmacológico, 2.ed. revisada e ampliada, Fortaleza: Edições UFC. 1995. $160 p$. 